\title{
Ceritinib: From Synthesis to Clinical Applications
}

\author{
Xiuyan Cui, Weihua Song, Qi Yang and Zhangqun Yang \\ Department of Pharmacy, Affiliated Hospital of Hebei University, Baoding 071000, Hebei, China
}

\begin{abstract}
Lung cancer is the major cause of cancer-related mortality, accountingfor over one quarter of cancer deaths. Lung cancers are generally divided into two main categories: SCLC (small cell lung cancer) and NSCLC (non-small cell lung cancer). NSCLC accounts for approximately $85 \%$ of all lung cancers. ALK (anaplastic largecell kinase) gene rearrangements are identified and targeted resulting in promising response rates for NSCLC in early studies. Ceritinib is a second-generation ALK inhibitor that has demonstrated activity in crizotinib (the first-generation ALK inhibitor)-resistant patients. In this paper, the synthesis, pharmacodynamics, pharmacokinetics, therapeutic trials, adverse events and drug-drug interactions are briefly overviewed in order to make more scholars, medical workers and patients have a more clear and comprehensive recognition on this drug.
\end{abstract}

Key words: Ceritinib, non-small cell lung cancer, ALK inhibitor, review.

\section{Introduction}

Ceritinib is an oral ALK (anaplastic lymphoma kinase) inhibitor synthesized by Michellys' group [1]. The capsule form (Zykadia $\left.{ }^{\circledR}\right)$ was approved by FDA (Food and Drug Administration) in 2014 [2]. ALK is a receptor tyrosine kinase of the insulin receptor superfamily [3]. The expression of ALK in tissues of health humans is only found in subset of neural cells [4]. The overexpression of ALK acts as a consequence of translocations or point mutations, which have been demonstrated to be an essential oncogenic lesion in a number of cancers especially for Lung cancer $[5,6]$. Lung cancer comprises $85 \%$ to $90 \%$ of cases classified as NSCLC (non-small-cell lung cancer) [7-9]. It has been found that $2 \sim 7 \%$ of NSCLC tumors express genetic alterations of the ALK genes $[10,11]$. ALK-positive tumors are highly sensitive to ALK inhibition, making such aberrations an important target for anticancer drug therapies.

Crizotinib is an anti-cancer drug acting as an ALK inhibitor and approved for treatment of NSCLC in the US and some other countries in 2010s [12, 13]. The undergoing clinical trials verified its safety and efficacy in anaplastic large cell lymphoma,

Corresponding author: Zhangqun Yang, Dr., research field: pharmacy. neuroblastoma, and other advanced solid tumors in both adults and children. However, the resistance to crizotinib has been reported in many patients receiving this agent and typically develops within one to two years of treatment [14]. As a result, the second-generation, oral tyrosine kinase inhibitor was developed to for the treatment of patients with ALK-positive metastatic NSCLC who have progressed on or are intolerant to crizotinib. In this paper, the synthesis, pharmacodynamics, pharmacokinetics, therapeutic trials and adverse events are briefly summarized in order to make more scholars, medical workers and patients have a more clear and comprehensive recognition on this drug.

\section{Synthesis}

The systematic name of Ceritinib is 4-(4-\{5-chloro-4-[2-(propane-2-sulfonyl)phenylamino] pyrimidin-2-ylamino -5-isopropoxy-2-methylphenyl) piperidine-1-carboxylic acid tert-butyl ester [15]. The structure and the synthetic route are shown in Figs. 1 and 2, respectively. The 2-Chloro-4-fluorotoluene is the starting compound for the synthesis of Ceritinib. The 2-Chloro-4-fluorotoluene is treated with $\mathrm{H}_{2} \mathrm{SO}_{4}$ and $\mathrm{KNO}_{3}$ under low temperature to give 2-chloro-4- 
<smiles>Cc1cc(Nc2ncc(Cl)c(Nc3ccccc3S(=O)(=O)C(C)C)n2)c(OC(C)C)cc1C1CCNCC1</smiles>

Fig. 1 The chemical structure of Ceritinib.

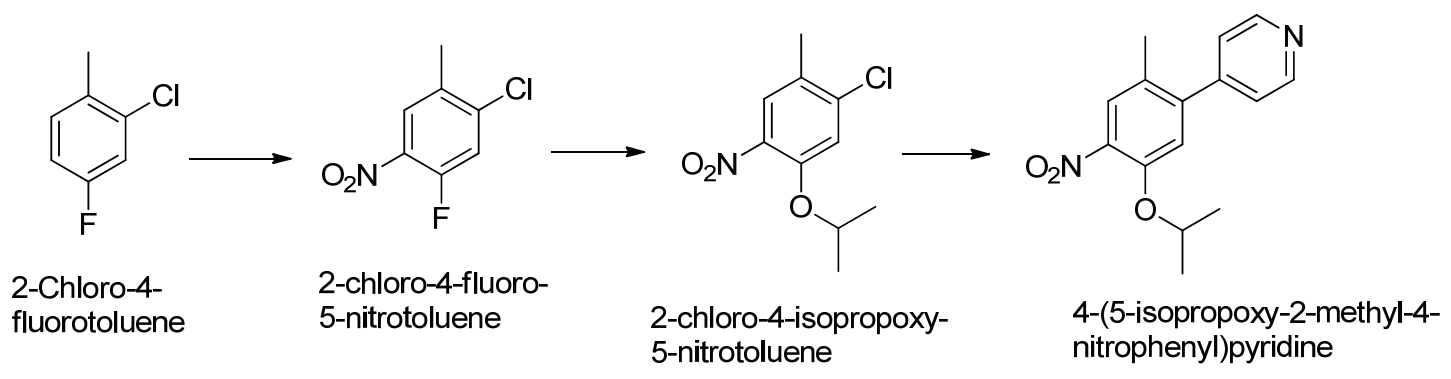<smiles>Cc1cc([N+](=O)[O-])c(OC(C)C)cc1C1CCN(C(=O)OC(C)(C)C)CC1</smiles>

4-(4-Amino-5-isopropoxy2-methylphenyl)piperidine-1carboxylic acid tert-butyl ester<smiles>Cc1cc(Nc2ncc(Cl)c(Nc3ccccc3S(=O)(=O)C(C)C)n2)c(OC(C)C)cc1C1CCNCC1</smiles>

(Ceritinib)

4-(4-\{5-chloro-4-[2-(propane-2sulfonyl)phenylamino]pyrimidin-2ylamino\}-5-isopropoxy-2-methylphenyl)piperidine1-carboxylic acid tert-butyl ester

Fig. 2 The synthetic route of Ceritinib.

fluoro-5-nitrotoluene as pale yellow oil and then the oil is reacted with 2-propanol under the catalysis of $\mathrm{Cs}_{2} \mathrm{CO}_{3}$ to give 2-chloro-4-isopropoxy-5-nitrotoluene. Then the obtained 2-chloro-4-isopropoxy-5nitrotoluene is mixed with 2-dicyclohexylphosphine2'-6'-dimethoxybiphenyl with the presence of $\mathrm{Pd}_{2} \mathrm{dba}_{3}$ and $\mathrm{K}_{3} \mathrm{PO}_{4}$ under nitrogen atmosphere to achieve 4-(5-isopropoxy-2-methyl-4-nitrophenyl) pyridine as a brown solid. 4-(5-Isopropoxy-2-methyl-4-nitrophenyl) pyridine undergoes a catalytic hydrogenation and then protected by di-tert-butyl dicarbonate $\left(\mathrm{Boc}_{2} \mathrm{O}\right)$ to give 4-(4-Amino-5-isopropoxy-2-methylphenyl)piperidine1 -carboxylic acid tert-butyl ester. The product is mixed with 2,5-dichloro- $N$-(2-(isopropylsulfonyl)-phenyl) pyrimidin-4-amine and then deprotected to give the final product (ceritinib).

\section{Pharmacodynamics}

Biochemical and cellular assays showed that ceritinib can inhibit ALK, IGF-1R (insulin-like growth factor I receptor), insulin receptor and ROSI at clinically relevant concentrations [16]. Ceritinib is more active against ALK than other above-mentioned target sites. The in vitro and in vivo assay results indicated that ceritinib inhibited the autophosphorylation of ALK, ALK-mediated phosphorylation of STAT3 (signal transducer and activator of transcription), as well as the proliferation 
of ALK-dependent cancer cells. The anti-tumour activity results showed that the proliferation of cell lines expressing EML4-ALK or nucleophosmin (NPM)-ALK fusion proteins in vitro and the growth of EML4-ALK-positive NSCLC xenografts in rodents. In a mouse xenograft tumour model derived from a lung cancer cell line (NCI-H2228) positive for EML4-ALK, complete tumour regression can be tracked after oral administration of ceritinib $25 \mathrm{mg} / \mathrm{kg} /$ day. Following treatment with ceritinib $50 \mathrm{mg} / \mathrm{kg} /$ day for 14 days, remission was maintained for months in this mouse xenograft tumour model. In addition, the dose of $50 \mathrm{mg} / \mathrm{kg} /$ day was effective in several NCI-H2228 tumour models that were resistant to the c-MET/ALK kinase inhibitor crizotinib, suggesting that ceritinib may be active in crizotinib-relapsed patients [17].

\section{Pharmacokinetics}

Based on recent reports, the maximum serum concentration $\left(C_{\max }\right)$ reaches $4 \sim 6 \mathrm{~h}$ after the oral administration of a single dose [18]. Dose-proportional increases can be tracked in the AUC (area under the curve) and $C_{\max }$ following doses of $50 \sim 750 \mathrm{mg} /$ day. The half-life $\left(t_{1 / 2}\right)$ of ceritinib is found to be approximately $40 \mathrm{~h}$, and the steady state can be reached in about 15 days. As compared to administration on an empty stomach, the AUC and $C_{\max }$ of ceritinib were $58 \%$ and $43 \%$ higher following a low-fat meal and $73 \%$ and $41 \%$ higher following a high-fat meal, respectively. Therefore, when dose is higher than $600 \mathrm{mg}$ taken with food, the ceritinib may have a greater systemic effect than a 750-mg dose taken on an empty stomach, leading to a raised potential for adverse reactions. As $97 \%$ of ceritinib is bound to human plasma protein, the volume of distribution following a single oral dose of $750 \mathrm{mg}$ is $4,230 \mathrm{~L}$. Metabolism occurs mostly via
CYP3A (cytochrome P450 3A). Following a 750-mg dose of radiolabeled ceritinib, $92.3 \%$ of the dose was recovered in feces and $1.3 \%$ was found in the urine. As the drug is primarily eliminated by the liver, moderate to severe hepatic impairment may interfere with clearance. The population pharmacokinetic data collected from 48 patients showed that ceritinib serum concentrations were similar in patients with mild hepatic impairment as compared to those with normal hepatic function. The results also showed that patients with mild to moderate renal impairment have similar exposure to ceritinib as compared to patients with normal renal function.

\section{Clinical Trials}

An ongoing, single-arm phase I study assessed the safety and efficacy of ceritinib has been reported [18]. 130 patients, 59 in the dose escalation phase and 71 in the expansion phase, were included in this trial. Among them, 94\% patients had NSCLC, 3\% patients had breast cancer, and 3\% patients had other ALK-positive tumors. In all, $68 \%$ of the NSCLC participants had received crizotinib prior. Among the NSCLC patients receiving a daily dose of greater than or equal to $400 \mathrm{mg}, 1 \%$ experienced a CR (complete response), $57 \%$ had a PR (partial response), 22\% had stable disease, and $11 \%$ experienced disease progression.

\section{Adverse Events}

The most common-adverse events and the relating

Table 1 The most common-adverse events and the relating incidence rates.

\begin{tabular}{ll}
\hline Events & Incidence rates (\%) \\
\hline Nausea & 82 \\
Diarrhea & 75 \\
Vomiting & 65 \\
Fatigue & 47 \\
Increased ALT level & 35 \\
\hline
\end{tabular}

Table 2 The reported drug interactions cases relating to ceritinib.

\begin{tabular}{ll}
\hline Drugs & Influence on ceritinib \\
\hline Rifampin (inducer of CYP3A) & Significant reduction in AUC and $C_{\max }$ \\
Ketoconazole (inhibitor of CYP3A) & Significant increases in AUC and $C_{\max }$ \\
\hline
\end{tabular}


incidence rates the in the above-mentioned clinical trial are summarized in Table 1 [18].

\section{Drug-Drug Interactions}

The coadministration of ceritinib and P-glycoprotein inhibitors or the agents that induce, inhibit, or are substrates of CYP3A or substrates of CYP2C9 often results in drug interactions [19]. Some drug interactions cases are summarized in Table 2 [1].

Therefore, if therapy with a potent inhibitor is medically required, the dose of ceritinib should be reduced. Otherwise, grapefruit and grapefruit juice consumption should also be avoided due to the potential inhibition of CYP3A.

\section{References}

[1] Cooper, M. R., Chim, H., Chan, H., and Durand, C. 2015. "Ceritinib: A New Tyrosine Kinase Inhibitor for Non-small-cell Lung Cancer." Annals of Pharmacotherapy 49: 107-12.

[2] Dhillon, S., and Clark, M. 2014. "Ceritinib: First Global Approval." Drugs 74: 1285-91.

[3] Mourali, J., Bénard, A., Lourenço, F. C., Monnet, C., Greenland, C., Moog-Lutz, C., et al. 2006. "Anaplastic Lymphoma Kinase Is a Dependence Receptor Whose Proapoptotic Functions Are Activated by Caspase Cleavage.” Molecular \& Cellular Biology 26: 6209-22.

[4] Kanaan, Z., Kloecker, G. H., Paintal, A., and Perez, C. A. 2015. "Novel Targeted Therapies for Resistant alk-Rearranged Non-Small-Cell Lung Cancer: Ceritinib and Beyond." Oncotargets \& Therapy 8: 885-92.

[5] Chiarle, R., Voena, C., Ambrogio, C., Piva, R., and Inghirami, G. 2008. "The Anaplastic Lymphoma Kinase in the Pathogenesis of Cancer." Nature Reviews Cancer 8: 11-23.

[6] Webb, T. R., Slavish, J., George, R. E., Look, A. T., Xue, L., Jiang, Q., et al. 2014. “Anaplastic Lymphoma Kinase: Role in Cancer Pathogenesis and Small-Molecule Inhibitor Development for Therapy." Expert Review of Anticancer Therapy 9: 331-56.

[7] Maione, P., Gridelli, C., Troiani, T., and Ciardiello, F. 2006. "Combining Targeted Therapies and Drugs with Multiple Targets in the Treatment of Nsclc." Oncologist 11: 274-84.

[8] Tsim, S., O’Dowd, C. A., Milroy, R., and Davidson, S. 2010. "Staging of Non-Small Cell Lung Cancer (NSCLC):
A Review." Respiratory Medicine 104: 1767-74.

[9] Zarogoulidis, K., Zarogoulidis, P., Darwiche, K., Boutsikou, E., Machairiotis, N., Tsakiridis, K., et al. 2013. "Treatment of Non-Small Cell Lung Cancer (NSCLC)." Journal of Thoracic Disease 5: S389-96.

[10] Hatanaka, H. 2007. "Identification of the Transforming Eml4-alk Fusion Gene in Non-small-cell Lung Cancer." Nature 448: 561-6.

[11] Shaw, A. T., and Solomon, B. 2011. "Targeting Anaplastic Lymphoma Kinase in Lung Cancer." Clinical Cancer Research 17: 2081-6.

[12] Ou, S. H. I., Bartlett, C. H., Mino-Kenudson, M., Cui, J., and Iafrate, A. J. 2012. "Crizotinib for the Treatment of ALK-Rearranged Non-small Cell Lung Cancer: A Success Story to Usher in the Second Decade of Molecular Targeted Therapy in Oncology." Oncologist 17: 1351-75.

[13] Rodig, S. J., and Shapiro, G. I. 2010. "Crizotinib, a Small-Molecule Dual Inhibitor of the C-met and ALK Receptor Tyrosine Kinases." Current Opinion in Investigational Drugs 11: 1477-90.

[14] Thomas, R. K. 2014. "Overcoming Drug Resistance in ALK-Rearranged Lung Cancer." New England Journal of Medicine 370: 1250-1.

[15] Marsilje, T. H., Pei, W., Chen, B., Lu, W., Uno, T., Jin, Y., et al. 2013. "Synthesis, Structure-Activity Relationships, and in vivo Efficacy of the Novel Potent and Selective Anaplastic Lymphoma Kinase (ALK) Inhibitor 5-chloro-n2-(2-isopropoxy-5-methyl-4-(piperidin-4-yl)ph enyl)-n4-(2-(isopropylsulfonyl)phenyl)pyrimidine-2,4-dia mi." Journal of Medicinal Chemistry 56: 5675-90.

[16] Li, N., Michellys, P. Y., Kim, S., Pferdekamper, A. M. C., Li, J., Kasibhatla, S., et al. 2011. "Activity of a Potent and Selective Phase I ALK Inhibitor LDK378 in Naive and Crizotinib-Resistant Preclinical Tumor Models." Presented at AACR-NCI-EORTC International Conference: Molecular Targets and Cancer Therapeutics, San Francisco, USA.

[17] Friboulet, L., Li, N., Katayama, R., Lee, C. C., Gainor, J. F., Crystal, A. S., et al. 2014. "The ALK Inhibitor Ceritinib Overcomes Crizotinib Resistance in Non-small Cell Lung Cancer." Cancer Discovery 4: 662-73.

[18] Shaw, A. T., Kim, D. W., Mehra, R., Tan, D. S., Felip, E., Chow, L. Q., et al. 2014. "Ceritinib in ALK-Rearranged Non-small-cell Lung Cancer." New England Journal of Medicine 370: 1189-97.

[19] Moore, C. D. 2014. "Drugs in Perspective: Zykadia (Ceritinib)." Formulary Journal. Accessed October 9, 2014. http://formularyjournal.modernmedicine.com/form ulary-journal/content/tags/alk-mutations/drug-overview-z ykadia-ceritinib. 